\title{
Substrate Influence on the Mechanical and Tribological Characteristics of Gold Thin Films for MEMS Applications
}

\author{
MERIE Violeta ${ }^{1, a^{*}}$, PUSTAN Marius ${ }^{2, ~ b}$, BîRLEANU Corina ${ }^{3, c}$, \\ NEGREA Gavril $^{4, \mathrm{~d}}$ and BELCIN OVIDIU ${ }^{5, \mathrm{e}}$ \\ 1, 2, 3,5 Technical University of Cluj-Napoca, Faculty of Machine Building, Department of Mechanical \\ Systems Engineering, 103-105 Muncii Avenue, 400641, Cluj-Napoca, Romania \\ ${ }^{4}$ Technical University of Cluj-Napoca, Faculty of Materials and Environmental Engineering, \\ Department of Materials Science and Engineering, 103-105 Muncii Avenue, 400641, Cluj-Napoca, \\ Romania \\ a *Violeta.Merie@stm.utcluj.ro, ${ }^{b}$ Marius.Pustan@omt.utcluj.ro, ${ }^{\mathrm{C} C}$ Corina.Barleanu@omt.utcluj.ro, \\ 'Gavril.Negera@ispm.utcluj.ro, ${ }^{\mathrm{e}}$ Ovidiu.Belcin@omt.utcluj.ro
}

Keywords: Gold thin films, thermal evaporation, MEMS applications, atomic force microscopy; nanoindentation.

\begin{abstract}
The development of micro- and nano- electromechanical systems (MEMS/NEMS) makes use of different thin films such as aluminum, gold, silicon, silver, titanium nitride, silicon carbide etc. This study is a research concerning the influence of substrate nature on the tribological and mechanical characteristics of gold thin films elaborated by thermal evaporation method, for space applications. Three different substrates were employed, namely: C45 steel, plastic (polycarbonate) and glass. Atomic force microscopy investigations were performed in order to characterize the obtained thin films at nanoscale. The nanohardness, Young's modulus, roughness and the friction force are some characteristics that were determined. A significant influence of substrate nature on both mechanical and tribological properties of researched gold thin films was marked out. Regarding the topography, the smallest roughness was determined on the gold thin films deposited on glass substrate.
\end{abstract}

\section{Introduction}

Nowadays, researcher's attention is focused on the development of miniaturized devices (microand nano- electromechanical systems) for applications in all domains (automotive, biomedical, electronics, space industries etc.). A wide range of materials used as bulk materials or thin films are employed for manufacturing such devices [1-7]. Gold as well as aluminum and silver is often used for elaborating devices for MEMS applications. The results of the researchers relating to gold thin films deposited by different chemical or physical methods are exploited in a large number of scientific articles [8-14].

The failure mechanisms in MEMS switches are adhesion, stiction and wear of ohmic contact phenomena. The ideal contact in this type of switches should be very conductive and flat. Gold is widely used in MEMS applications due to its high conductivity and chemical inertness. In spite that we need to improve the hardness of this metal by incorporating different particles such as cooper, nickel, silver, palladium platinum etc. [8]. Its high electrical conductivity, optical reflectivity as well as its low Young's modulus (79 GPa) make gold suitable for manufacturing micro- devices for MEMS applications [14].

Physical vapor deposition, plasma-assisted chemical vapor deposition, laser ablation, RF reactive sputtering, reactive evaporation, ion-beam deposition and so forth are some techniques employed for fabricating thin films for MEMS devices. 
The goal of this paper is to elaborate and characterize gold thin films by thermal evaporation method on different substrates in order to emphasize its influence on the mechanical and tribological properties.

\section{Materials and methods}

\section{Materials}

Gold thin films were deposited on three different materials in order to highlight substrate influence on the mechanical and tribological characteristics of the elaborated samples. The materials employed for substrates were C45 steel, plastic (polycarbonate) and glass respectively. Gold target with the purity of $99.99 \%$ was employed. The process of elaboration of the samples was performed in a chamber under vacuum protection.

\section{Methods}

Gold thin films were elaborated by the thermal evaporation method. First, the three kinds of substrates were prepared. Cylindrical samples, $15 \mathrm{~mm}$ in diameter, made of C45 steel were first cut and then rectified and polished with flints of granulation up to 1200. The plastic and glass substrates were cut in square shape having the dimensions of $25 \times 25 \mathrm{~mm}$. Further, the three types of substrates were cleaned in an ultrasonic bath for removing any possible remaining impurities using high purity alcohol $(99.9 \%)$. The samples were then dried with hot air. The so-obtained substrates were then introduced in the chamber under vacuum protection where the deposition of gold thin films was realized. The thermal evaporation process was done under vacuum atmosphere $\left(5 \cdot 10^{-6}\right.$ torr $)$. The substrates were not preheated before gold deposition. The melting and the evaporation of the gold were realized by using resistance heated tungsten sources ("boat" type). The resistors were charged to a current of 60-80 A so that the process can take place. The distance between the resistors and the substrates was $50 \mathrm{~mm}$. The thickness of the obtained gold thin films was determined to be about 70 $\mathrm{nm}$. The following notation was settled for the obtained samples in order to facilitate the interpretation of the results: "Au_substrate nature" (example: "Au_glass" represents the gold thin films samples deposited on glass substrate).

The so-obtained samples were characterized from the mechanical and tribological point of view at nanoscale. The nanocharacterization of the researched samples was performed in a clean environment using a XE 70 atomic force microscope. The determination of the tribological characteristic (friction force) and the surface parameter (roughness) for the researched thin films was realized using a PPP-CONTSCR-10M cantilever. The tip of this cantilever is made of silicon. Its radius and height are $8 \mathrm{~nm}$ and $12.5 \mu \mathrm{m}$ respectively. The tests were effectuated for a relative humidity of about $50 \%$ at room temperature $\left(22^{\circ} \mathrm{C}\right)$. The scanning frequency was $0.75 \mathrm{~Hz}$. According to the data given by the producer, the dimensions of the cantilever used for investigations are:

- thickness: $\mathrm{h}=1 \mu \mathrm{m}$;

- $\quad$ width: $b=48 \mu \mathrm{m}$;

- length: $1=225 \mu \mathrm{m}$.

The mechanical characteristics (Young's modulus and nanohardness) of the studied materials were determined by nanoindentation tests which employed a TD21562 nanoindentor (sapphire cantilever with diamond tip). The characteristics of the nanoindentor given by the manufacturer are:

- $\quad$ cantilever stiffness: $144 \mathrm{~N} / \mathrm{m}$;

- $\quad$ cantilever length: $782 \mu \mathrm{m}$;

- $\quad$ tip thickness: $24 \mu \mathrm{m}$;

- $\quad$ tip height: $109 \mu \mathrm{m}$;

- $\quad$ tip radius: $25 \mathrm{~nm}$;

- inclination: $12^{\circ}$;

- $\quad$ front, half and side angles: 90,30 and $79^{\circ}$. 
The tests were carried out at two different forces limit namely $50 \mathrm{nN}$ and $100 \mathrm{nN}$ respectively. The XEI Image Processing Tool for SPM data used the Oliver and Pharr method for the interpretation of the images obtained with the XEP Data Acquisition Program for the determination of the mechanical properties.

\section{Theoretical formula}

The determination of friction force was one of the aims of the researchers in order to characterize the obtained thin films from the tribological point of view at a nanoscale. Friction force can be calculated based on the data provided by the employed atomic force microscope using the following formula [15]:

$$
F_{f}=\frac{d_{z} \cdot r \cdot G \cdot h^{3} \cdot b}{l^{2} \cdot s}
$$

where $d_{z}$ represents tip rotational deflection, $r$ is a constant $(r=0.33)$, $G$ is shear modulus (for silicon: $\mathrm{G}=53.9 \cdot 10^{-3} \mathrm{~N} / \mu \mathrm{m}^{2}$ ), $\mathrm{h}, \mathrm{b}$ and $\mathrm{l}$ are the dimensions of the cantilever, while $\mathrm{s}$ is tip height ( $\mathrm{s}$ $=12.5 \mu \mathrm{m})$.

The values of tip rotational deflection are taken from the data offered by the program used for interpreting the images acquired with XEP Data Acquisition Program (XEI Image Processing Tool for SPM data).

\section{Results and discussions}

The research aimed at determining the mechanical and tribological properties of gold thin films elaborated by thermal evaporation method by atomic force microscopy investigations. Tests were performed in order to analyze the topography of the obtained samples measuring their roughness at the same time. Nanohardness and Young's modulus are the mechanical characteristics that were determined, while the friction force between the tip and sample surface is the tribological property of interest.

\section{Topography}

3D images of the obtained gold thin films were achieved using the XEI Image Processing Tool for SPM data (Fig. 1). The gold thin films deposited on glass substrates presents the smoothest surface from all three kind of samples while the gold thin films deposited on plastic substrates showed the roughest surface. The roughness of the researched samples was determined in order to sustain the previous statement.

An important influence of the substrate on this parameter was marked out. The values determined for surface parameter are given in Table 1. The average roughness ranged between about $3 \mathrm{~nm}$ for the samples deposited on glass substrate and about $30 \mathrm{~nm}$ for the samples deposited on plastic surface. The roughness of gold thin films elaborated on glass is approximately 3.5 and 8.5 times smaller than the roughness of the gold thin films elaborated on steel and plastic substrates respectively. A possible explanation might be the topography of the substrate which has a significant influence on the topography of the gold thin films. The preparation of the substrates has also an important impact on the surface parameter - plastic surfaces are the most difficult to process from the three material used for substrates.

Table 1. Roughness $\left(\mathrm{R}_{\mathrm{a}}\right)$ of the researched samples

\begin{tabular}{|c|c|c|c|}
\hline Material & Gold_glass & Gold_plastic & Gold_steel \\
\hline Roughness, $\mathrm{R}_{\mathrm{a}}(\mathrm{nm})$ & 3.553 & 30.187 & 11.943 \\
\hline
\end{tabular}




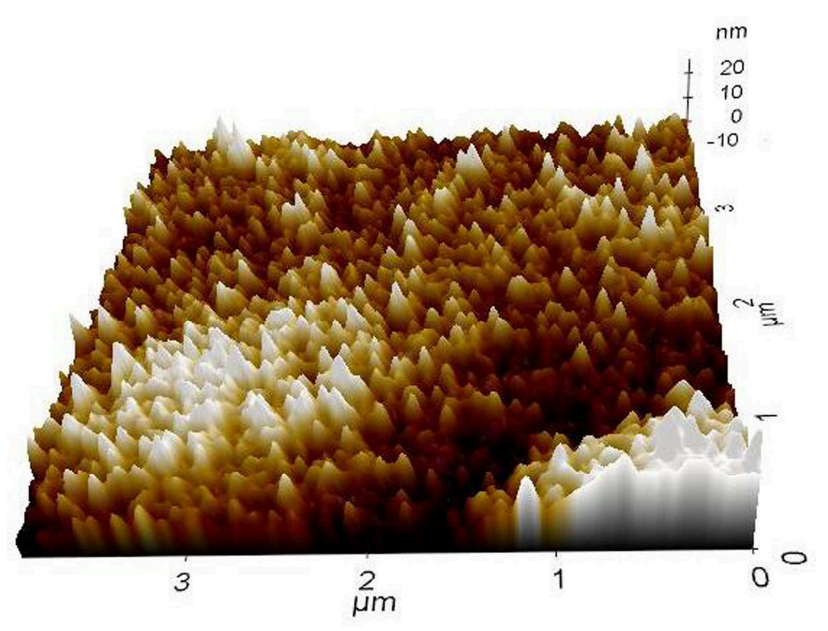

(a)

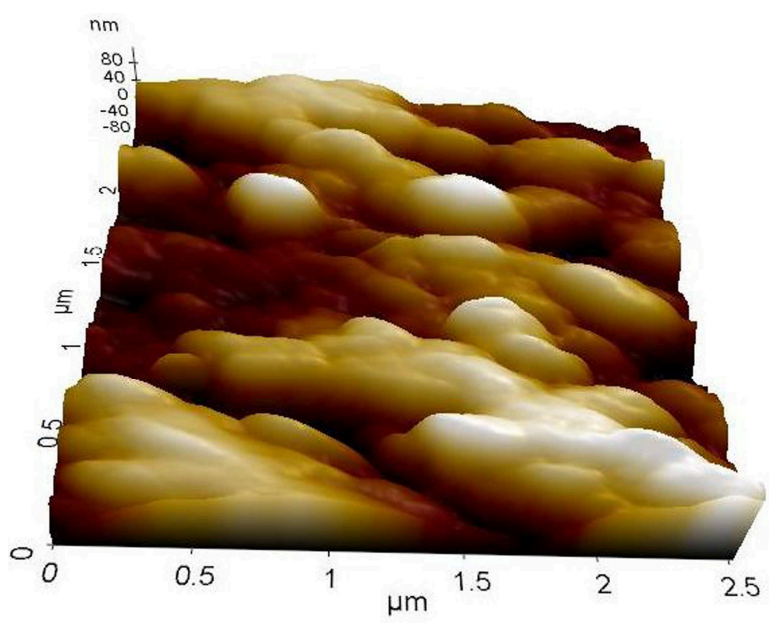

(b)

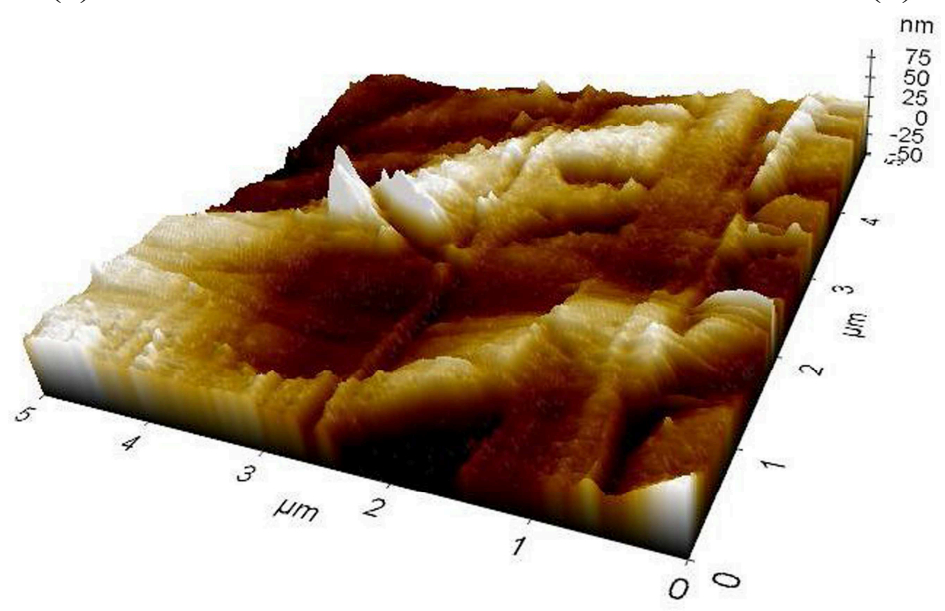

(c)

Fig. 1. 3D images of gold thin films deposited on (a) glass, (b) plastic and (c) steel substrates respectively

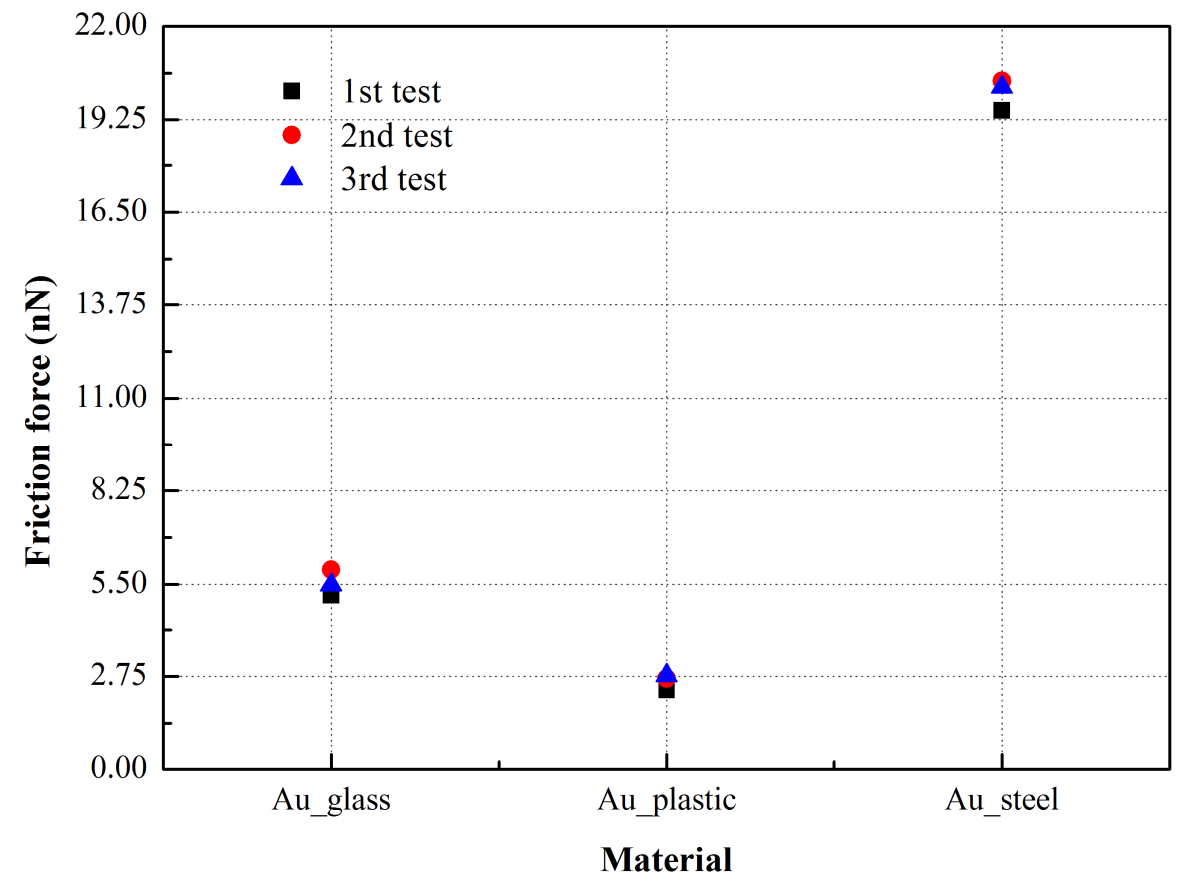

Fig. 2. Friction force between AFM tip and gold thin films deposited on glass, plastic and steel respectively 
The fluctuation of the friction force between the AFM tip and the surfaces for the three types of samples is graphically given in Fig. 2. The smallest and the closest values for the friction parameter were determined on the gold thin film elaborated on plastic substrates. Instead the values of the friction force for the samples deposited on glass and steel substrates were approximately two and eight times higher respectively than the friction force of the samples deposited on plastic substrates. The variation of the friction force may be due to the fact that each sample presents a different surface energy.

The determination of both mechanical characteristics (nanohardness and Young's modulus) was realized using the Oliver and Pharr method for the interpretation of the force- $Z$ scan curves achieved with the XEP Data Acquisition Program. Fig. 3 presents a force- $Z$ scan curve characteristic to a gold thin film deposited on glass substrate.

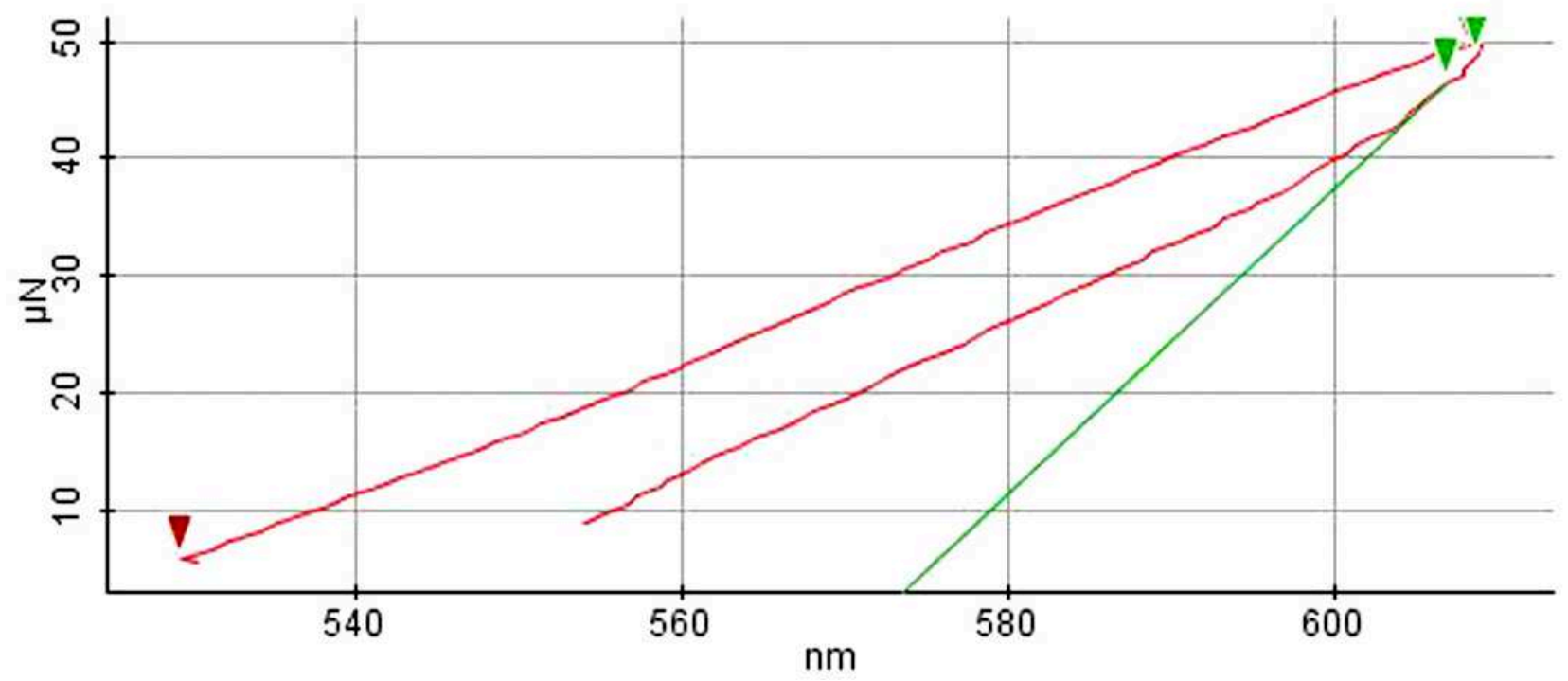

Fig. 3. Force-Z scan curve of a gold thin film deposited on glass substrate for determining the mechanical characteristics

Nanohardness of the researched thin films obtained by thermal evaporation when testing with two forces limit (50 and $100 \mathrm{nN}$ respectively) is graphically given in Fig. 4. A significant impact on this mechanical characteristic of substrate nature was highlighted. As expect, the values of this parameter when the samples were tested with $50 \mathrm{nN}$ are higher than the values for the samples tested with $100 \mathrm{nN}$. The increase of the force limit leads to the decrease of the nanohardness for the samples elaborated on the same substrate. The gold thin films deposited on steel substrate presented the highest values of the nanohardness when force limit was $50 \mathrm{nN}$, while the gold thin films deposited on glass substrate showed the highest values of this parameter when force limit was 100 $\mathrm{nN}$. If the nanohardness of the samples elaborated on steel substrates is approximately $16 \%$ higher than that of the samples deposited on glass substrates, the nanohardness of the samples elaborated on plastic substrates is about $50 \%$ smaller than that of the samples deposited on steel and glass substrates.

Concerning the Young's modulus of the studied gold thin films, the results marked out a significant influence of substrate nature on this characteristic. The values of Young's modulus for the three kinds of samples tested with 50 and $100 \mathrm{nN}$ are graphically given in Fig. 5. As the nanohardness of researched samples, the values of Young's modulus decreases when the force limit increases. The highest value of this parameter was determined for the gold thin films deposited on glass substrate when the force limit was $50 \mathrm{nN}$, while the smallest value of Young's modulus was determined for the samples elaborated on plastic substrates when the force limit was $100 \mathrm{nN}$. 


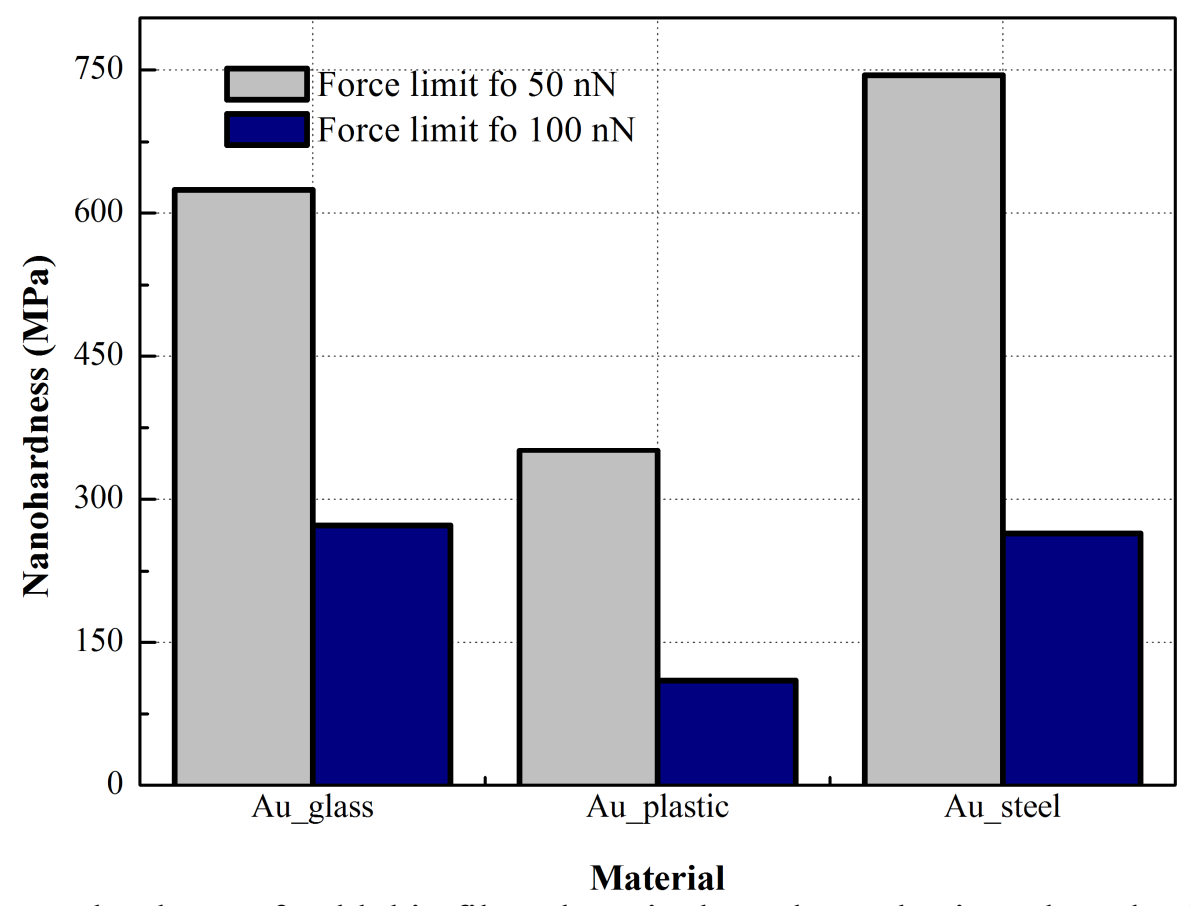

Fig. 4. Nanohardness of gold thin films deposited on glass, plastic and steel substrates

When the tests were performed with a force limit of $50 \mathrm{nN}$, the Young's modulus of gold thin films deposited on glass substrates is approximately 5 and $30 \%$ higher than the Young's modulus of the samples elaborated on steel and plastic substrates respectively. Instead when a force limit of $100 \mathrm{nN}$ was employed, the Young's modulus of gold thin films deposited on steel substrates is about 13 and $26 \%$ higher than the Young's modulus of the samples deposited on glass and plastic substrates respectively.

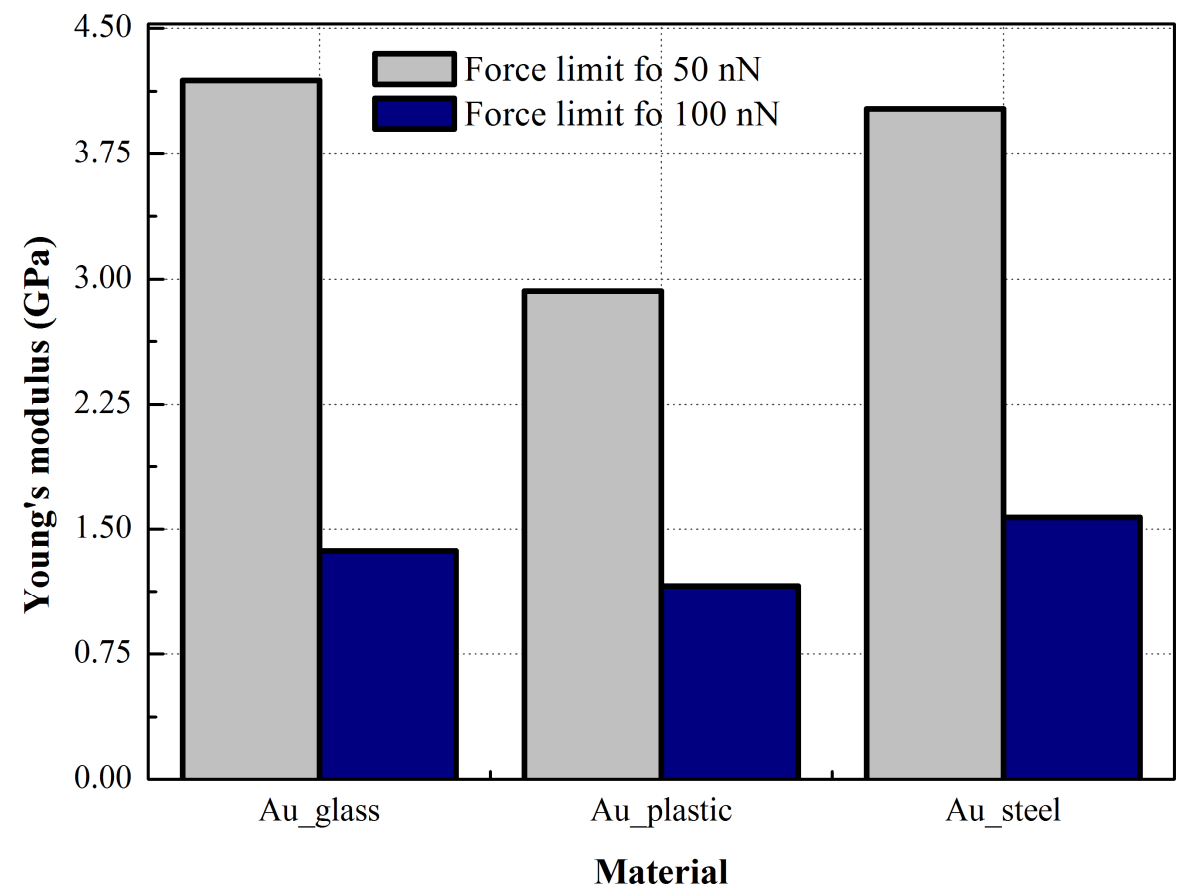

Fig. 5. Young's modulus of gold thin films deposited on glass, plastic and steel substrates

The explanation for the fluctuation of both mechanical characteristics might be the surface energies that differ for each sample. The chemical bonds that appear between the gold thin films and the substrate material (glass, steel, and plastic respectively) have different intensities that lead to different surface energies. 
Figure 6 present images of the gold thin films deposited on steel substrate after the nanoindentation tests. The traces left on the sample by the nanoindentor when testing with 50 and $100 \mathrm{nN}$ are marked out on the 3D image. The results also aimed at determining the depth of the traces. The value measured for the depth of the trace obtained when a force limit of $100 \mathrm{nN}$ was employed is about three times higher than the value of the depth for the trace obtained when the force limit was $50 \mathrm{nN}$.
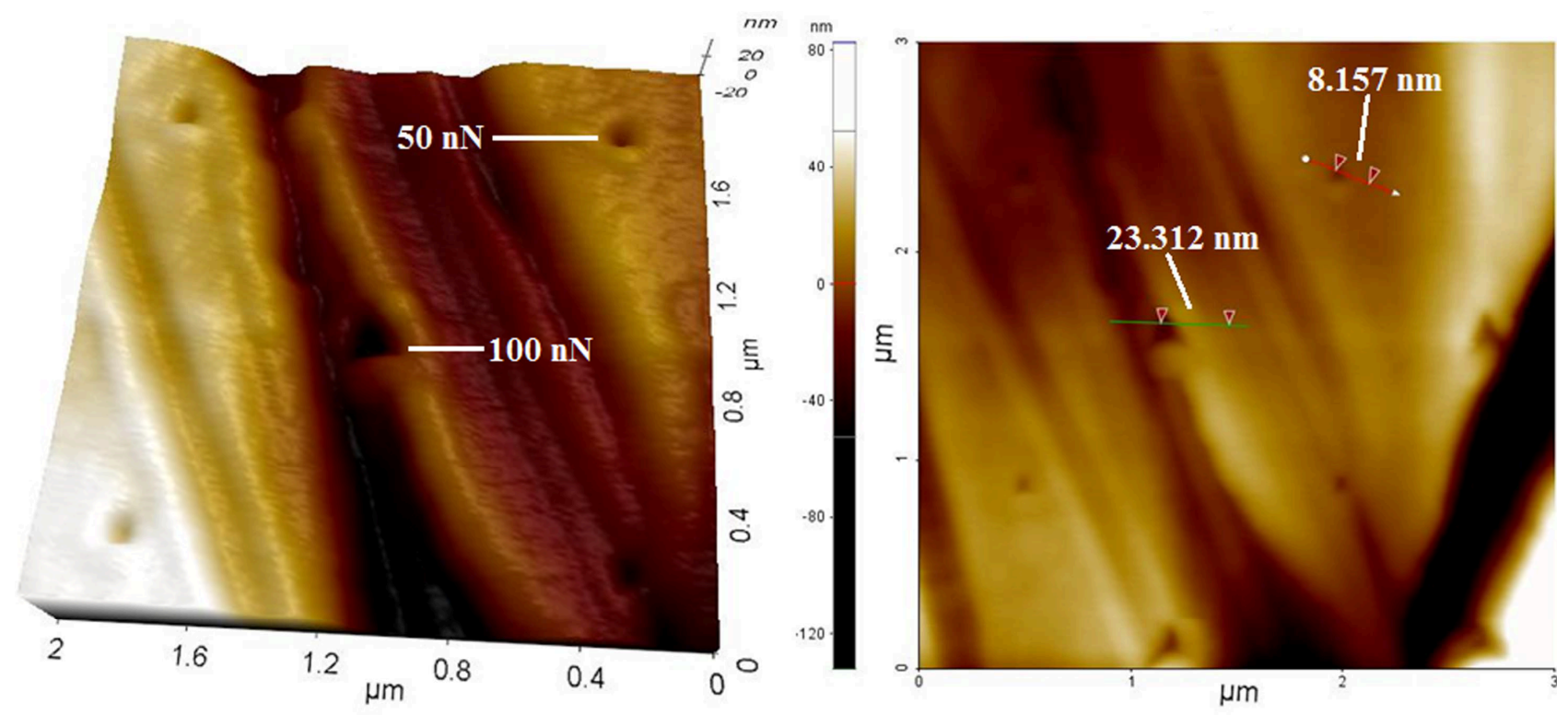

Fig. 6. Images of the traces left on the gold thin film deposited on steel substrate after the nanoindentation tests

Note: The depth of the traces when testing with 50 and $100 \mathrm{nN}$ is $8.157 \mathrm{~nm}$ and $23.213 \mathrm{~nm}$ respectively

\section{Conclusions}

A significant influence of substrate nature on the mechanical and tribological characteristics of gold thin films deposited by thermal evaporation was marked out. Three different substrates were employed in order to achieve this purpose, namely glass, plastic and steel. The topography of the elaborated gold thin films is strongly influence by the topography of the substrate and by substrate preparation. The gold thin films deposited on glass substrate are characterized by the smallest value of the roughness and implicitly by the smoothest surface. Regarding the tribological behavior, the highest value for the friction force between the AFM tip and the sample surface were determined for the gold thin films deposited on steel substrates. The nanoindentation tests showed a considerable change of both nanohardness and Young's modulus when different forces limit and different substrates were used. The increase of the force limit led to the decrease of the mechanical characteristics. The highest value of nanohardness was determined on the gold thin films deposited on steel substrate when testing with a force limit of $50 \mathrm{nN}$, while the highest value of Young's modulus was achieved on the gold thin films elaborated on glass substrate when a force limit of 50 $\mathrm{nN}$ was employed.

\section{Acknowledgments}

This work was supported by a FP7 Grant type MNT-ERA.NET no. 7-064/2012 “3-Scale modeling for robust-design of vibrating micro sensors". 


\section{References}

[1] S. Petroni, C. La Tegola, G. Caretto, A. Campa, A. Passaseo, M. De Vittorio, R. Cingolani, Aluminum Nitride piezo-MEMS on polyimide flexible substrates, Microelectron. Eng. 88 (2011) 2372-2375.

[2] J. Martinez-Quijada, S. Caverhill-Godkewitsch, M. Reynolds, L. Gutierrez-Rivera, R.W. Johnstone, D.G. Elliott, D. Sameoto, C.J. Backhouse, Fabrication and characterization of aluminum thin film heaters and temperature sensors on a photopolymer for lab-on-chip systems, Sens. Actuators, A 193 (2013) 170-181.

[3] X.J. He, Z.Q. Lv, B. Liu, Z.H. Li, High-isolation lateral RF MEMS capacitive switch based on $\mathrm{HfO}_{2}$ dielectric for high frequency applications, Sens. Actuators, A 188 (2012) 342-348.

[4] Z. Wang, J. Liu, T. Ren, L. Liu, Fabrication of organic PVP doping-based Ba0.5Sr0.5TiO3 thick films on silicon substrates for MEMS applications, Sens. Actuators, A 117 (2005) 293-300.

[5] Y. Cao, S. Allameh, D. Nankivil, S. Sethiaraj, T. Otiti, W. Soboyejo, Nanoindentation measurements of the mechanical properties of polycrystalline $\mathrm{Au}$ and $\mathrm{Ag}$ thin films on silicon substrates: Effects of grain size and film thickness, Mater. Sci. Eng., A 427 (2006) 232-240.

[6] I.C. Estrada-Raygoza, M. Sotelo-Lerma, R. Ramirez-Bon, Structural and morphological characterization of chemically deposited silver films, J. Phys. Chem. Solids 67 (2006) 782-788.

[7] G.M. Wilson, J.F. Smith, J.L. Sullivan, A nanotribological study of thin amorphous C and $\mathrm{Cr}$ doped amorphous C coatings, Wear 265 (2008) 1633-1641.

[8] V. Mulloni, R. Bartali, S. Colpo, F. Giacomozzi, N. Laidani, B. Margesin, Electrical and mechanical properties of layered gold-chromium thin films for ohmic contacts in RF-MEMS switches, Materials Science and Engineering B 163 (2009) 199-203.

[9] O. Okman, J.W. Kysar, Fabrication of crack-free blanket nanoporous gold thin films by galvanostatic dealloying, Journal of Alloys and Compounds 509 (2011) 6374-6381.

[10] M. Kim,W.J. Ha, J.W. Anh, H.S. Kim, S.W. Park, D. Lee, Fabrication of nanoporous gold thin films on silicon substrate by multilayer deposition of $\mathrm{Au}$ and $\mathrm{Ag}$, Journal of Alloys and Compounds 484 (2009) 28-32.

[11] J.F. Pierson, D. Wiederkehr, A. Billard, Reactive magnetron sputtering of copper, silver, and gold, Thin Solid Films 478 (2005) 196-205.

[12] F. Aviles, O. Ceh, A.I. Oliva, Physical properties of Au and Al thin films measured by resistive heating, Surface Review and Letters 12 (2005) 101-106.

[13] A. Proszynski, D. Chocyk, G. Gladyszewski, Stress modification in gold metal thin films during thermal annealing, Optica Applicata XXXIX (2009) 705-710.

[14] B. Moazzez, S.M. O’Brien, E.F. Merschrod S., Improved adhesion of gold thin films evaporated on polymer resin: Applications for sensing surfaces and MEMS, Sensors 13(2013) 70217032.

[15] V. Merie, M. Pustan, C. Birleanu, Nanocharacterization of some Fe-based friction composites, ACTA Technica Napocensis. Series: Applied Mathematics and Mechanics 56 (2013) 709-714. 